\title{
VA Primary Care and Mental Health Providers' Comfort with Genetic Testing: Survey Results from the PRIME Care Study
}

\author{
Leland E. Hull, M.D. ', Kevin G. Lynch, Ph.D. ${ }^{2,3}$, and David W. Oslin, M.D. ${ }^{2,3}$ \\ ${ }^{1}$ Center for Healthcare Organization and Implementation Research, VA Boston Healthcare System, Boston, MA, USA; ${ }^{2}$ Perelman School of \\ Medicine, University of Pennsylvania, Philadelphia, PA, USA; ${ }^{3}$ Corporal Michael J. Crescenz VA Medical Center, Philadelphia, PA, USA.
}

J Gen Intern Med 34(6):799-801

DOI: $10.1007 / \mathrm{s} 11606-018-4776-0$

(c) Society of General Internal Medicine (This is a U.S. government work and not under copyright protection in the U.S.; foreign copyright protection may apply) 2018

\section{INTRODUCTION}

Pharmacogenetic (PGx) tests could transform how we prescribe medications. PGx tests assess whether a patient has specific genetic variants that could affect their likelihood of treatment response or risk of an adverse drug reaction. ${ }^{1}$ Currently, providers may order a variety of genetic tests in their clinical practice, including tests for disease susceptibility and diagnosis. PGx tests likely represent the next wave of genetic testing offered in the clinic, especially given the development of PGx test panels. PGx test panels check for multiple genedrug interactions to guide medication selection for common conditions, such as depression and chronic pain. Anticipating that adoption of these tests will continue to expand as part of routine clinical care, we felt it important to delineate provider's current knowledge of and experience with PGx testing.

Few surveys have assessed physicians' knowledge and attitudes towards PGx. ${ }^{2,3}$ In this report, we present data from a baseline survey of primary care providers (PCPs) and mental health providers (MHPs) enrolled in the PRecision medicine In MEntal health (PRIME) Care study, a Department of Veterans Affairs (VA) clinical trial assessing the utility of PGx for treatment of major depressive disorder (MDD). ${ }^{4}$

\section{METHODS}

PRIME Care MHPs and PCPs enrolled in the study could refer patients with MDD for PGx testing. Site principal investigators (PIs) used individual and group outreach to recruit and enroll eligible MHPs and PCPs. At enrollment, providers completed a baseline survey with questions adapted from the literature ${ }^{3}$ that included the following: (1) demographic questions, (2) Likert-type questions to assess self-rated comfort with genetic test utilization (response choices included: strongly agree, somewhat agree, neutral, somewhat disagree, strongly disagree, and prefer not to answer), (3) multiplechoice questions assessing genetic test order frequency, and (4) yes/no questions assessing knowledge about PGx drug

Published online January 2, 2019 labelling. Practice location was used to classify providers as MHPs or PCPs and compare responses. Likert-type responses were collapsed to determine the proportion of providers in agreement (strongly agree or somewhat agree) with the statements. MHP and PCP responses were compared using $t$ tests (continuous outcomes) and chi-squared tests (categorical outcomes) using SAS 9.4 (Cary, NC).

\section{RESULTS}

From July 11, 2017, to February 13, 2018, 342 prescribers from 19 sites completed the survey. Ten providers were excluded from the analyses because they either could not be classified as a MHP or PCP $(n=2)$ or could not order the panel $(n=8)$. Most providers practiced in a mental health care setting, were female, were White non-Hispanic, had completed their clinical training after year 2000, and spent $>50 \%$ of their time in clinical practice (Table 1). Only a quarter of providers were aware that the FDA has revised drug labels to include information about PGx. Less than $15 \%$ of either group had ordered a PGx test to guide psychotropic medication prescribing. Ordering genetic tests for disease susceptibility or diagnosis were more common among PCPs than among MHPs.

More MHPs felt well-informed about genetic testing and comfortable ordering a PGx test (Fig. 1), whereas PCPs were more comfortable ordering genetic tests for disease susceptibility. The minority of providers reported access to genetics expertise. Less than a third felt that their genetics training was adequate for clinical practice.

\section{DISCUSSION}

Among PRIME Care providers, few had experience ordering genetic testing in general, and PGx testing specifically, in the past year. The minority of PCPs expressed comfort ordering any genetic test, access to genetics expertise, and feeling that their genetics training is adequate for clinical practice; PCPs expressed the most comfort ordering genetic tests for disease susceptibility (e.g., BRCA testing for breast and ovarian cancer risk). Given the expansion of genomic medicine, these findings highlight the need to develop educational initiatives, provide expert consultation, and integrate decision support 
Table 1 Baseline Characteristics of the Providers $(N=332)$

\begin{tabular}{|c|c|c|c|c|}
\hline Characteristic & $\begin{array}{l}\text { All providers } \\
(N=332)\end{array}$ & $\begin{array}{l}\text { Primary care } \\
\text { providers }(N=93)\end{array}$ & $\begin{array}{l}\text { Mental health } \\
\text { providers }(N=239)\end{array}$ & $p$ value \\
\hline Mean age, years (standard error) & $\begin{array}{l}49.9(12.6) \\
N(\%)\end{array}$ & $\begin{array}{l}49.9(11.2) \\
N(\%)\end{array}$ & $\begin{array}{l}49.8(13.1) \\
N(\%)\end{array}$ & 0.97 \\
\hline Sex & & & & \\
\hline $\begin{array}{l}\text { Female } \\
\text { Male }\end{array}$ & $\begin{array}{l}182(55 \%) \\
150(45 \%)\end{array}$ & $\begin{array}{l}52(56 \%) \\
41(44 \%)\end{array}$ & $\begin{array}{l}130(54 \%) \\
109(46 \%)\end{array}$ & 0.80 \\
\hline Race & & & & \\
\hline $\begin{array}{l}\text { White non-Hispanic } \\
\text { Other }\end{array}$ & $\begin{array}{l}216(65 \%) \\
116(35 \%)\end{array}$ & $\begin{array}{l}64(69 \%) \\
29(31 \%)\end{array}$ & $\begin{array}{l}152(64 \%) \\
87(36 \%)\end{array}$ & 0.37 \\
\hline $\begin{array}{l}\text { Profession } \\
\text { Physician } \\
\text { Non-physician prescriber }\end{array}$ & $\begin{array}{l}263(79 \%) \\
69(21 \%)\end{array}$ & $\begin{array}{l}21(23 \%) \\
72(77 \%)\end{array}$ & $\begin{array}{l}48(20 \%) \\
191(80 \%)\end{array}$ & 0.61 \\
\hline $\begin{array}{l}\text { Year completed formal training } \\
2000 \text { or before } \\
\text { After } 2000\end{array}$ & $\begin{array}{l}149(45 \%) \\
183(55 \%)\end{array}$ & $\begin{array}{l}56(60 \%) \\
37(40 \%)\end{array}$ & $\begin{array}{l}93(39 \%) \\
146(61 \%)\end{array}$ & $<0.001$ \\
\hline $\begin{array}{l}\text { Time spent in clinical practice } \\
0-49 \% \\
50 \% \text { or more }\end{array}$ & $\begin{array}{l}48(14 \%) \\
284(86 \%)\end{array}$ & $\begin{array}{l}21(23 \%) \\
72(77 \%)\end{array}$ & $\begin{array}{l}27(11 \%) \\
212(89 \%)\end{array}$ & 0.009 \\
\hline $\begin{array}{l}\text { Aware that the FDA-revised drug labels to include information about PGx } \\
\text { Ordered a genetic test for disease susceptibility or diagnosis in the past year } \\
\text { Ordered a PGx test for psychotropic medications in the past year }\end{array}$ & $\begin{array}{l}87(26 \%) \\
72(22 \%) \\
42(13 \%)\end{array}$ & $\begin{array}{l}18(19 \%) \\
40(43 \%) \\
7(8 \%)\end{array}$ & $\begin{array}{l}69(29 \%) \\
32(13 \%) \\
35(15 \%)\end{array}$ & $\begin{array}{l}0.08 \\
<0.001 \\
0.08\end{array}$ \\
\hline
\end{tabular}

FDA, Food and Drug Administration; PGx, pharmacogenetic

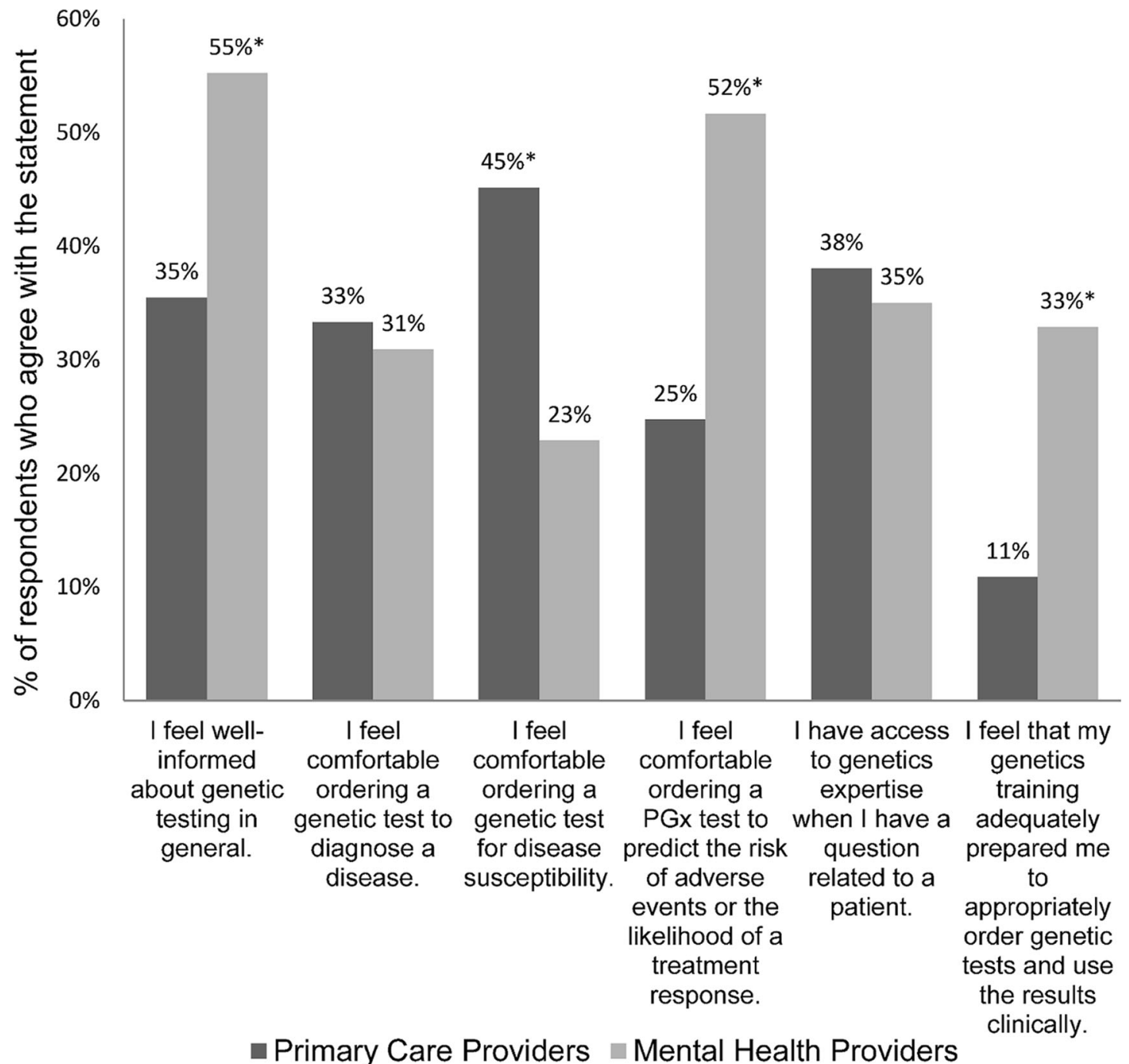

Figure 1 Primary care versus mental health providers' self-rated knowledge and comfort with genetic testing. * $p$ value $<0.05$. PGx, pharmacogenetic. 
tools in clinical care to facilitate appropriate genetic test utilization and uptake. ${ }^{5}$

A limitation of this study is selection bias. We do not know how many providers were approached about enrollment and how representative the providers who consented to the study are compared to those who did not enroll. It is likely that enrolled providers may be PGx enthusiasts and/or early adopters; therefore, providers in the general population may be even less comfortable with genetic tests than the providers enrolled in this study. This only reinforces the need to train and provide guidance for providers using these tests.

Corresponding Author: Leland E. Hull, M.D.; Center for Healthcare Organization and Implementation Research, VA Boston Healthcare System, Boston, MA, USA (e-mail: leland.hull@va.gov).

Contributors We are grateful to the PRIME Care site principal investigators and their teams who enrolled and administered the survey to study providers: Muhammad Aslam, MD; Steven L. Batki, MD; Frederic Blow, PhD; James M. Bjork, PhD; Lisa Brenner, PhD; Peijun Chen, MD, PhD; Shivan Desai, MD; Eric Dieperink, MD; Richard Douyon, MD, FAPA; Scott Fears MD, PhD; Joel Gelernter, MD; Gretchen Haas, PhD; Amy Helstrom, PhD; Robin Hurley, MD; George Jurjus, $M D$; Julie Kreyenbuhl, PhD, PharmD; Steven Lieske, $M D, P h D$; Stephen Marder, MD; Cristina Montalvo, MD; Michael Ostacher, MD; Gayla Paschall, PhD; Paul Pfeiffer, MD; Jeffrey Pyne, MD; Mohin Ranganathan, MD; Joseph Simonetti, MD; Courtney Slough-Goodman, PharmD; Stuart Steinhauer, PhD; Trisha Suppes, MD, PhD; George Uhl, MD, PhD; Jason Vassy, MD; Gerardo Villarreal, MD; Amanda Wood, $P h D$.
Funding Information Dr. Hull is supported by the Department of Veterans Affairs Office of Academic Affiliations Advanced Fellowship Program in Health Services Research, the Center for Healthcare Organization and Implementation Research (CHOIR), VA Boston Healthcare System. This research was funded by a VA Office of Research and Development awarded to Dr. David Oslin (SDR 16-348; ClinicalTrials.gov ID: NCT03170362).

\section{Compliance with Ethical Standards:}

This study was approved by the Department of Veterans Affairs Central Institutional Review Board.

Conflict of Interest: The authors declare that they do not have a conflict of interest.

Publisher's Note Springer Nature remains neutral with regard to jurisdictional claims in published maps and institutional affiliations.

\section{REFERENCES}

1. Relling MV, Evans WE. Pharmacogenomics in the clinic. Nature 2015;526:343-50.

2. Stanek EJ, Sanders CL, Taber KA, et al. Adoption of pharmacogenomic testing by US physicians: results of a nationwide survey. Clin Pharmacol Ther. 2012;91:450-8.

3. Haga SB, Burke W, Ginsburg GS, Mills R, Agans R. Primary care physicians' knowledge of and experience with pharmacogenetic testing. Clinical genetics 2012; 82:388-94.

4. PRIME Care (PRecision Medicine In MEntal Health Care). Available at: https://clinicaltrials.gov/ct2/show/NCT03170362. Accessed 10/31/18.

5. Haga SB, Moaddeb J. Comparison of delivery strategies for pharmacogenetic testing services. Pharmacogenet Genomics 2014;24:139-45. 